\title{
A comparison of the efficacy of varenicline and bupropion and an evaluation of the effect of the medications in the context of the smoking cessation programme
}

\author{
Ali Ramazan Benli ${ }^{1 *}$, Selman Erturhan ${ }^{2}$, Muhammet Ali Oruc ${ }^{3}$, Pinar Kalpakci ${ }^{4}$, Didem Sunay ${ }^{1}$ and Yeltekin Demirel $^{5}$
}

\begin{abstract}
Background: Within the context of the support program for smoking cessation, initiated by the Turkish Ministry of Health in 2011, those who present at 'smoking cessation' centres and are found to be suitable for pharmacological treatment are given varenicline and bupropion free of charge. As the smoking cessation programme is centralized, the selection of the medication is made randomly to provide a fixed distribution rate. The aim of this study was to evaluate the efficacy of both varenicline and bupropion in smoking cessation and to evaluate the effect of the smoking cessation programme.
\end{abstract}

Methods: A total of 405 individuals who met the study criteria were included in the study. Smoking habits and degree of dependence were determined in all the participants with the Fagerstrom test for nicotine dependence (FTND) and bupropion or varenicline therapy was initiated in those who were eligible. Patients were followed up at 15 days then at 1, 2, 3, 6 and 12 months after smoking cessation. A level of $\mathrm{CO}<5 \mathrm{ppm}$ and 'point prevalence abstinence' were used as the criteria of success for smoking cessation and this evaluation showed the non-smoking status in the previous 7 days.

Results: The mean age of the participants was $35.19 \pm 7.73$ years and $82.8 \%(n=334)$ were male. Of the participants, $60.2 \%(n=244)$ were given varenicline and 39.8\% $(n=161)$ bupropion. The mean FTND and package/ year was not significantly different between the groups. The rates of success in the 1st and 2nd weeks, and 1st, 3rd and 6 th months were significantly higher in the varenicline group than in the bupropion group $(p<0.05)$. At the end of one year, the rate of smoking cessation was determined as 13.9\% $(n=34)$ in the varenicline group and 6.2\% $(n=10)$ in the bupropion gruop. The difference was statistically significant $(p=0.015)$. At the end of 1 year when the previous 7 days smoking status was evaluated with the 'point prevalence abstinence' measurement as the success criteria, success rates were $20.5 \%$ with varenicline and $18.6 \%$ with bupropion and the difference was not significant $(p=0.646)$. The individuals who used the medications for 45 days or longer were more successful in smoking cessation $(p<0.001)$. The most common reasons given for discontinuing the medication were the sideeffects (31.5\%). No significant difference was determined between the groups in respect of the side-effects observed.

\footnotetext{
* Correspondence: dralibenli@gmail.com

'Department of Family Medicine, Karabuk University, Medical Faculty, 78000

Karabuk, Turkey

Full list of author information is available at the end of the article
} 
(Continued from previous page)

Conclusions: Although the rates of smoking cessation in all the other control points were higher with varenicline than with bupropion, no significant difference was found between the success rates of varenicline and bupropion used in smoking cessation based on the last 7 days at the end of one year. Those who used the medications for 45 days or longer were more successful in smoking cessation.

Keywords: Varenicline, Bupropion, Smoking cessation

\section{Background}

Smoking is addictive in nature because of the psychoactive nicotine substance contained in tobacco. The risk of dependence in smoking is similar to that in heroin and alcohol use [1]. Smoking is one of the most important causes of four diseases which are the most common causes of mortality (atherosclerotic cardiovascular disease, cerebrovascular disease, cancer and chronic obstructive pulmonary disease) The development of smoking-related diseases and the associated risks of death significantly decrease in persons who quit smoking [2]. Therefore, one should seek help from both the immediate vicinity and professionals. Pharmacological support is an important component of smoking cessation and should be recommended to those want to quit [2-4].

Despite increased understanding of the harmful effects, smoking has recently become almost an epidemic. A new tobacco control period was initiated by the World Health Organization in 2003 within the context of action against smoking and the Framework Convention on Tobacco Control (FCTC) contract was published. Turkey signed that contract in 2004 and adopted it in the same year with Law no 5261. In accordance with that contract, the "National Tobacco Control Program" and the "Tobacco Control Action Plan" covering 2008-2012 were prepared with the participation of a large number of representatives from official and nongovernmental organizations. Vareniclin tartrate (Champix ()) and bupropion hydrochloride (Zyban $\odot$ ) which are used in smoking cessation were distributed free of charge in the smoking cessation clinics (SCC) for a 3-month period [5]. This increased applications to smoking cessation clinics. During this period, that there was an increase of 8.8 fold in the number of applications to our clinic was an encouraging finding in favour of the campaign. Patients who were to receive the medication were randomly determined by the medication support center in order to provide a constant distribution rate of varenicline and bupropion and so that physicians would not be aware of the medication distribution. This created an open experimental setup for comparison of the rate of success between varenicline and bupropion.

In this context, the aim of the study was to evaluate the efficacy of both varenicline and bupropion in the cessation of smoking and the effect of the smoking cessation programme. In addition, compliance of individuals to using the medications and side effects were evaluated.

\section{Methods}

Our polyclinic has been in service since 1999, providing behavioural therapy support with a biopsychosocial approach to individuals wishing to stop smoking and recommending pharmacological methods and where possible monitoring the patients with proactive telephone calls and follow-up visits. Patients can apply to the clinic directly by calling the Ministry of Health 'stop smoking' helpline and making an appointment.

This study was designed as a prospective, comparative study. During the study period of March 2011-October 2011, a total of 2397 individuals aged over 18 years applied to our smoking cessation polyclinic and were included in the smoking cessation programme of the Ministry of Health. After smoking cessation, the participants were evaluated at 15 days then at $1,2,3,6$ and 12 months. Patients who did not attend the follow-up visits were called by telephone. A total of 405 individuals completed one year of follow-up and agreed to participate in the study.

A questionnaire was completed at face-to-face interviews. The questionnaire included sociodemographic characteristics of the participants and questions related to alcohol consumption (unit/day; 1 unit alcohol =1glass of wine, 1 bottle of beer, 1 measure of spirits), smoking status since stopping, medication use and if used irregularly, the reasons why (patients were not guided in this), side-effects, confidence in their ability to be successful in smoking cessation ( $0-5$ points; 0 : no, 1 : very low, 2 : low, 3:medium; 4:high, 5:very high), whether or not there was another smoker at home, support from family and friends and previous attempts to stop smoking. In addition to the physical examination, the Fagerstrom Test for Nicotine Dependence (FTND) was applied [6].

In the period of medication support, the medicines to be used by patients specifically in this period were distributed free of charge by the Ministry of Health. Persons considered eligible after presentation were given one of the two medications (varenicline or bupropion) by the support center. Since nicotine replacement was not included in the program, this study only evaluated 
the bupropion and vareniclin therapies. The participants were informed about the frequent possible side effects of the medications. Of the total participants, $60.2 \%$ $(n=244)$ were given vareniclin and $39.8 \%(n=161)$ bupropion. Patients receiving treatment for previously known psychiatric disease and those with epilepsy were excluded from the study.

\section{Fagerstrom Test for Nicotine Dependence (FTND)}

FTND is a widely used scale in the determination of nicotine dependence. The Turkish version of FTND has been tested for reliability. FTND consists of 6 questions scored between 1 and 10 points with a score of $>4$ points indicating the possibility of dependence. Based on the total score obtained from a comprehensive evaluation of this test; nicotine dependence is graded in 5 categories as very low ( $0-2$ points), low (3-4 points), medium ( 5 points), high (6-7 points) and very high (8-10 points) [6].

\section{Evaluation of side effects}

Questions were asked about the possible side effects to achieve a standard conclusion and to learn if there were side effects that the patients could not recall, but might have experienced. In addition, other side effects reported by the patients were recorded and the side effects specified by the patients were combined if they were very similar.

\section{Measurement of $\mathrm{CO}$ level in breath}

The monitoring of smoking status was implemented by measuring the $\mathrm{CO}$ level in the breath using a 'Bedfontpico + Smokerlyzer' monitor in the clinic at every visit. In the $\mathrm{CO}$ measurement in the breath, participants were first asked to perform a forced expiration and then a full inhalation following by holding their breath until a beep sound from the device (about $15 \mathrm{~s}$ ) and then to blow slowly into the mouthpiece, aiming to empty the lungs completely. For subjects who reported that they had not smoked in the previous 7 days, the $\mathrm{CO}$ measurements were performed twice at $5 \mathrm{~min}$ intervals. A level between 6 and $10 \mathrm{ppm}$ indicated an infrequent smoker or danger zone, while $11 \mathrm{ppm}$ and higher values indicated an addicted smoker with high levels of $\mathrm{CO}$ in their blood. In the present study, a $\mathrm{CO}$ level $\leq 5 \mathrm{ppm}$ was considered as the success criterion as proposed by Perkins et al. [7].

The 'point prevalence abstinence' measurement, as in the American Public Health Service guidelines, was used to determine the success rate in smoking cessation [8]. This evaluation expresses the smoking status in the previous 7 days and has been widely used in previous studies as it provides a general result and increases statistical power [9].

\section{Statistical analysis}

Statistical analysis of the data was performed utilizing the SPSS v20.0 Statistical Software. Definitive statistics were expressed as mean rank and difference for continuously measured variables and as frequency and percentage for nominal variables. Relationships between variables were evaluated using correlation analysis. The Chi-square test was used for categorical variables, while variables specified with measurement were evaluated through the Independent Samples $t$-test. A value of $p<0.05$ was considered statistically significant.

Approval for this study was granted by the Local Ethics Committee.

\section{Results}

Of the total 405 participants, $82.5 \%(n=334)$ were male and $17.5 \%(n=71)$ female. The age of the patients ranged from 20 to 65 years. The overall mean age was $35.24 \pm 7.7$ years, while the mean age was $35.09 \pm$ 7.85 years in males and $36.03 \pm 6.88$ years in females (Table 1). The mean FTND value at presentation was determined as $6.34 \pm 2.38$ for varenicline and $6.23 \pm 2.49$ for bupropion $(p=0.655)$, while package/year values were $14.8 \pm 7$ and $15.9 \pm 6$, respectively $(p=0.624)$.

At the end of one year, the success rate was found to be $20.5 \%$ with varenicline and $18.6 \%$ with bupropion based on 7 -day point prevalence $(p=0.646)$. In persons who used the medications for 45 days or longer, the one-year success rates were determined as 27.6 and $27.8 \%$ for varenicline and bupropion based on 7-day point prevalence $(p=0.987)$. The CO levels of all the participants were measured and found to be $<5 \mathrm{ppm}$ in 80 participants who stated that they had not smoked during the previous week (mean CO level, $2.36 \pm 0.90$ ).

Of the total participants, $3.95 \%(n=16)$ never used the medication, while $6.7 \%(n=27)$ used the medication regularly. Regular use of the medication over 90 days was determined in $9.8 \%(n=24)$ of the varenicline users and $1.9 \%(n=3)$ of the bupropion users $(p=0.002)$. Medication use of 71 days or longer was determined in 34 (13.7\%) varenicline and $6(3.7 \%)$ bupropion users $(p=0.001)$. The rate of medication use for at least 45 days was determined as $25.9 \%$ $(n=105)$ (varenicline; $n=87$, bupropion; $n=18)(p<0.001)$.

The demographic characteristics and smoking habits of the participants are shown in Table 1. No significant differences were observed between the groups in respect of gender, age, marital status, educational level, BMI, presence of another smoker at home, alcohol consumption, social support, previous quitting attempts, concerns about the harmful effects of smoking, Fagerstrom scores or the age of starting to smoke. However, there was a significant difference between the groups in terms of the amount of smoking, with a higher rate determined in the varenicline group than in the bupropion group $(p=0.004)$. 
Table 1 The demographical characteristics and smoking habits of participants

\begin{tabular}{|c|c|c|c|c|c|c|}
\hline \multirow[t]{2}{*}{ Variable } & & \multicolumn{2}{|c|}{ Varenicline $(n=244)$} & \multicolumn{2}{|c|}{ Bupropion $(n=161)$} & \multirow[t]{2}{*}{$p^{*}$} \\
\hline & & $n$ & $\%$ & $n$ & $\%$ & \\
\hline \multirow[t]{2}{*}{ Gender } & Male $(n=334)$ & 194 & 79.5 & 140 & 87.0 & \multirow[t]{2}{*}{0.054} \\
\hline & Female $(n=71)$ & 50 & 20.5 & 21 & 13.0 & \\
\hline \multirow[t]{3}{*}{ Age Groups } & $20-29(n=111)$ & 74 & 30.3 & 37 & 23.0 & \multirow[t]{3}{*}{0.267} \\
\hline & $30-39(n=184)$ & 106 & 43.4 & 78 & 48.4 & \\
\hline & $\geq 40(n=110)$ & 64 & 26.2 & 46 & 28.6 & \\
\hline \multirow[t]{2}{*}{ Marital Status } & Married $(n=329)$ & 191 & 78.3 & 138 & 85.7 & \multirow[t]{2}{*}{0.061} \\
\hline & Not Married $(n=76)$ & 53 & 21.7 & 23 & 14.3 & \\
\hline \multirow[t]{3}{*}{ Educational Status } & Primary- Secondary & 45 & 18.4 & 31 & 19.3 & \multirow[t]{3}{*}{0.775} \\
\hline & High School & 101 & 41.4 & 71 & 44.1 & \\
\hline & College $+{ }^{a}$ & 98 & 40.2 & 59 & 36.6 & \\
\hline \multirow[t]{2}{*}{ Alcohol Consumption Status } & Yes $(n=63)$ & 37 & 15.2 & 26 & 16.163 & \multirow[t]{2}{*}{0.789} \\
\hline & No $(n=342)$ & 207 & 84.8 & 135 & 83.9 & \\
\hline \multirow[t]{2}{*}{ Social support } & Yes $(n=241)$ & 169 & 69.3 & 75 & 65.2 & \multirow[t]{2}{*}{0.394} \\
\hline & No $(n=161)$ & 75 & 30.7 & 86 & 34.8 & \\
\hline \multirow{4}{*}{$\begin{array}{l}\text { The amount of cigarettes smoked per day in } \\
\text { the initial presentation }\end{array}$} & $1-10$ pcs & 29 & 11.9 & 5 & 3.1 & \multirow[t]{4}{*}{0.004} \\
\hline & $11-20$ pcs & 99 & 40.6 & 86 & 53.4 & \\
\hline & $21-30$ pcs & 79 & 53.4 & 43 & 26.7 & \\
\hline & $\geq 31$ pcs & 37 & 45.7 & 27 & 16.8 & \\
\hline \multirow[t]{2}{*}{ Previous quitting trial } & Yes $(n=272)$ & 167 & 68.4 & 105 & 65.2 & \multirow[t]{2}{*}{0.499} \\
\hline & No $(n=133)$ & 77 & 31.6 & 56 & 34.8 & \\
\hline \multirow[t]{4}{*}{ Concerns about the harmful effects of smoking } & No $(n=24)$ & 16 & 6.6 & 8 & 5.0 & \multirow[t]{4}{*}{0.532} \\
\hline & Little $(n=69)$ & 45 & 18.4 & 24 & 14.9 & \\
\hline & High $(n=170)$ & 96 & 39.3 & 74 & 46.0 & \\
\hline & Very High $(n=142)$ & 87 & 35.7 & 55 & 34.2 & \\
\hline \multicolumn{2}{|l|}{ Mean Fagerstrom Score } & \multicolumn{2}{|c|}{$6.34 \pm 2.38$} & \multicolumn{2}{|c|}{$6.23 \pm 2.49$} & $0.655^{* *}$ \\
\hline \multicolumn{2}{|c|}{ The amount of cigarettes/day in the initial presentation } & \multicolumn{2}{|c|}{$22.78 \pm 10.11$} & \multicolumn{2}{|c|}{$23.39 \pm 9.13$} & 0.540 \\
\hline \multicolumn{2}{|l|}{ Mean Age } & \multicolumn{2}{|c|}{$34.8 \pm 7.61$} & $35.9 \pm$ & & 0.124 \\
\hline Mean age of start to begin smoking & & 17.80 & & 17.60 & & 0.635 \\
\hline Mean Body Mass Index & & 25.46 & & 26.11 & & 0.082 \\
\hline
\end{tabular}

${ }^{*}$ Chi square test, ${ }^{* *}$ Independent sample $t$ test (in evaluation of mean values)

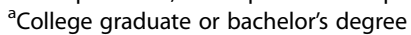

Based on the patient self, the period with the highest rate of success was the first two weeks after the day of cessation. The rates of success in the first and second weeks were significantly different in favour of varenicline $(p<0.001)$. The rate of success in the first month was determined as $48.4 \%$ in varenicline and $33.5 \%$ in bupropion users $(p=0.003)$. When the subjects who did not smoke in the first 3 months were evaluated, the varenicline users were found to be significantly more successful than the bupropion users $(p=0.003)$. The difference between the two groups continued at the end of 6 months and at the end of one year, the rate of the smoking cessation was found to be $13.9 \%(n=34)$ in the varenicline group and $6.2 \%(n=10)$ in the bupropion group with a statistically significant difference $(p=0.015)$ (Table 2).

Open-ended questions were asked about the reasons for taking the medication, but not using it regularly and the answers given were categorized. Those who participated in the campaign because it was free of charge although they did not feel ready to quit smoking or did not believe that the medication would be effective were determined at the rate of $10.1 \%$. After exclusion of 27 individuals who used the medications regularly, the final assessment was applied to 378 participants. The first or the most remarkable reasons reported by the participants are given in Table 3 in order of frequency. According to this, $30 \%$ of those using varenicline and $33.5 \%$ of 
Table 2 Comparisons of smoking cessation of medication groups in follow-up

\begin{tabular}{|c|c|c|c|c|c|c|c|}
\hline \multirow[t]{2}{*}{ Period } & \multicolumn{2}{|c|}{$\begin{array}{l}\text { Varaenicline } \\
(n=244)\end{array}$} & \multicolumn{2}{|c|}{$\begin{array}{l}\text { Bupropion } \\
(n=161)\end{array}$} & \multicolumn{2}{|c|}{$\begin{array}{l}\text { Total } \\
(n=405)\end{array}$} & \multirow[t]{2}{*}{$p^{*}$} \\
\hline & $\mathrm{n}$ & $\%$ & $\mathrm{n}$ & $\%$ & $\mathrm{n}$ & $\%$ & \\
\hline First week & 158 & 64.8 & 75 & 46.6 & 233 & 57.5 & $<0.001$ \\
\hline First 2 weeks & 143 & 58.6 & 63 & 39.1 & 206 & 50.9 & $<0.001$ \\
\hline First 1 month & 118 & 48.4 & 54 & 33.5 & 172 & 42.5 & 0.003 \\
\hline First 3 months & 76 & 31.1 & 29 & 18.0 & 105 & 25.9 & 0.003 \\
\hline First 6 months & 48 & 19.7 & 16 & 9.9 & 64 & 15.8 & 0.009 \\
\hline First 1 year & 34 & 13.9 & 10 & 6.2 & 44 & 10.9 & 0.015 \\
\hline
\end{tabular}

*Chi-square test

those using bupropion, stated side effects as the reason for not using the medication regularly. With the exception of 16 subjects who never used the medications, $62.2 \%(n=242)$ of the remaining 389 individuals reported that they developed at least one side effect. Of the total 234 varenicline users, $143(61.1 \%)$ reported that they experienced at least one side effect, while this rate was $98(63.2 \%)$ of 155 bupropion users $(p=0.674)$. The 5 most common side effects were nausea, insomnia, headache, fatigue, irritability and the 5 side effects most commonly self-reported in the study were insomnia, nausea, irritability, headache and dry mouth.

When the factors affecting the success of smoking cessation were evaluated in 80 participants who quit smoking, the rate of success was higher among those who did not drink alcohol, used the medication for 45 days or longer or had experienced multiple failed attempts to quit smoking $(p<0.05)$. The cessation of smoking rate in the previous 7 days of those who used the medications for 45 days or more was $27.6 \%$ in the varenicline group and $27.8 \%$ in the bupropion group. No significant differences were observed between the groups in respect of other parameters (Table 4).

\section{Discussion}

In this study, the overall success rate of both medications in smoking cessation was found to be $19.8 \%$ at the end of the first year. Based on the patient statements, the uninterrupted rate of cessation (URC) of varenicline was found to be higher in the first month, in the first three months, 5-12 weeks, in the first 6 months and the entire year. At the end of one year, the rate of smoking cessation was determined as $13.9 \%$ in the varenicline group and $6.2 \%$ in the bupropion group. However, when the 'point prevalence abstinence' measurement of the American Public Health Service guidelines, was used as the criteria of success in smoking cessation in the previous 7 days at the end of 1 year, the rate of success was determined as $20.5 \%$ for varenicline and $18.6 \%$ for bupropion. No statistically significant difference was found between the medications.

In a systematic review by Cahill et al., varenicline was superior to single forms of NRT (OR 1.57; 95\% CI, 1.29 to 1.91), and to bupropion (OR 1.59; 95\% CI, 1.29 to 1.96),

Table 3 Comparisons of causes of irregular medication usage of groups

\begin{tabular}{|c|c|c|c|c|c|}
\hline \multirow[t]{2}{*}{ The cause of irregular medication usageuse } & \multicolumn{2}{|c|}{$\begin{array}{l}\text { Varenicline } \\
(n=220)\end{array}$} & \multicolumn{2}{|c|}{$\begin{array}{l}\text { Bupropion } \\
(n=158)\end{array}$} & \multirow[t]{2}{*}{$P^{*}$} \\
\hline & $\bar{n}$ & $\%$ & $\mathrm{n}$ & $\%$ & \\
\hline Side effects & 66 & 30 & 53 & 33.5 & 0.464 \\
\hline Over self-confidence/no more need for medicationthe drug & 48 & 21.8 & 17 & 10.8 & 0.005 \\
\hline Not to see any effect of the drugmedication & 14 & 6.4 & 21 & 13.3 & 0.022 \\
\hline Not feel exactly ready to quit smoking & 14 & 6.4 & 16 & 10.1 & 0.182 \\
\hline Fail to quit smoking & 18 & 8.2 & 6 & 3.8 & 0.085 \\
\hline Begin to smoke again & 14 & 6.4 & 8 & 5.1 & 0.594 \\
\hline Fear of side effects & 10 & 4.5 & 6 & 3.8 & 0.722 \\
\hline Inability to come controls & 7 & 3.2 & 7 & 4.4 & 0.526 \\
\hline Not to believe effect of the medicationdrug & 6 & 2.7 & 5 & 3.2 & 0.803 \\
\hline Increased in desiremand to smoke & 4 & 1.8 & 4 & 2.5 & 0.635 \\
\hline $\begin{array}{l}\text { ThinkDesire to quit the to not to take the medication anddrug smoking } \\
\text { at the same dday of smoking cessation }\end{array}$ & 3 & 1.4 & 4 & 2.5 & 0.406 \\
\hline Work schedule & 3 & 1.4 & 1 & 0.6 & 0.493 \\
\hline Since the drug is bupropion & 0 & 0 & 4 & 2.5 & 0.018 \\
\hline ToNot dis like using medicationine & 2 & 0.9 & 0 & 0 & 0.229 \\
\hline Not to take the drug with them & 1 & 0.5 & 2 & 1.3 & 0.381 \\
\hline Noncompliant & 10 & 4.5 & 4 & 2.5 & 0.307 \\
\hline
\end{tabular}

*Chi square test 
Table 4 Parameters that considered to effect quitting success

\begin{tabular}{|c|c|c|c|c|}
\hline Parameters & & $\mathrm{n}$ & $\%$ & $P^{*}$ \\
\hline \multirow[t]{2}{*}{ Gender } & Male $(n=334)$ & 61 & 18.3 & 0.102 \\
\hline & Female $(n=71)$ & 19 & 26.8 & \\
\hline \multirow[t]{3}{*}{ Age } & $20-29(n=111)$ & 28 & 25.2 & 0.234 \\
\hline & $30-39(n=184)$ & 33 & 17.9 & \\
\hline & $\geq 40(n=110)$ & 19 & 17.3 & \\
\hline \multirow[t]{2}{*}{ Marital status } & Married $(n=329)$ & 64 & 19.5 & 0.752 \\
\hline & Not married $(n=76)$ & 16 & 21.1 & \\
\hline \multirow[t]{2}{*}{ Education } & $\begin{array}{l}\text { Primary, secondary, high } \\
\text { school }(n=248)\end{array}$ & 42 & 16.9 & 0.804 \\
\hline & University $(n=157)$ & 38 & 24.2 & \\
\hline \multirow[t]{2}{*}{ Alcohol consumption } & Yes $(n=63)$ & 5 & 7.9 & 0.01 \\
\hline & No $(n=342)$ & 75 & 21.9 & \\
\hline \multirow[t]{2}{*}{ Social support } & Yes $(n=274)$ & 50 & 18.2 & 0.271 \\
\hline & No $(n=131)$ & 30 & 22.9 & \\
\hline \multirow[t]{2}{*}{ Previous quitting attempts } & $\leq 1$ time $(n=133)$ & 41 & 15.5 & 0.003 \\
\hline & $>1$ time $(n=272)$ & 39 & 27.7 & \\
\hline \multirow{4}{*}{$\begin{array}{l}\text { Concern about harmful } \\
\text { effects of smoking }\end{array}$} & No $(n=24)$ & 8 & 33.3 & 0.028 \\
\hline & Little $(n=69)$ & 19 & 27.5 & \\
\hline & High $(n=170)$ & 34 & 20.0 & \\
\hline & Very high $(n=142)$ & 19 & 13.4 & \\
\hline \multirow[t]{2}{*}{ Receiving medication } & $\geq 45$ days $(n=105)$ & 29 & 27.6 & 0.019 \\
\hline & $<45$ days $(n=300)$ & 51 & 17.0 & \\
\hline \multirow{2}{*}{$\begin{array}{l}\text { Self-confidence about } \\
\text { quitting }\end{array}$} & $0-4$ points $(n=303)$ & 52 & 17.2 & 0.024 \\
\hline & 5 points $(n=102)$ & 28 & 27.5 & \\
\hline \multirow{2}{*}{$\begin{array}{l}\text { Another person smoking } \\
\text { in house }\end{array}$} & Yes $(n=142)$ & 29 & 20.4 & 0.804 \\
\hline & $\mathrm{No}(n=263)$ & 51 & 19.4 & \\
\hline
\end{tabular}

${ }^{*}$ Chi square test

but was not more effective than combination NRT (OR 1.06; 95\% CI, 0.75 to 1.48) [10]. However, in that review, the outcome for benefit was continuous or prolonged abstinence for at least six months from the start of treatment [11]. In meta-analyses by Hughes et al. [12] good results were found to be related to varenicline compared to bupropion. In another systematic review which examined 10 studies, findings suggested that varenicline groups achieved higher rates of abstinence compared to both NRT and placebo, bupropion and NRT were of similar effectiveness, and bupropion and varenicline both had higher abstinence rates compared to placebo [13]. No statistically significant difference in terms of side effects was seen in either medication.

$\mathrm{CO}$ measurement is frequently used to confirm smoking cessation. In a recent study, a CO titer of $5 \mathrm{ppm}$ was stated to be the most optimal value containing both sensitivity and specificity [7]. Likewise in the present study, a $C O$ level $\leq 5 \mathrm{ppm}$ was accepted as the criterion of success. In the current study, the rate of success based on 7-day point prevalence was found to be 20.5 and $18.6 \%$ for varenicline and bupropion, respectively. The difference was not statistically significant. In literature, 1-year rates of success based on 7-day point prevalence have been reported as 26.2 and $30.5 \%$ for varenicline and between 20.7 and $35 \%$ for bupropion [14-16].

In previous studies about smoking cessation, the mean age has ranged between 37.8 and 46.2 years [17-19]. Although there have been national and international studies reporting that age does not influence smoking cessation outcomes $[17,20]$, some studies have found that an older age has a positive influence on the success of smoking cessation [12, 14-21]. The relatively lower mean age in the current study may be a factor in the lower success rate of cessation.

In this study, the rate of regular medication use over 3 months was $6.7 \%$. In a previous study evaluating the use of varenicline therapy, $28.2 \%$ of the participants continued the therapy for 3 months. In the same study, the rate of success was significantly higher in the group which received therapy for 3 months or longer [22]. In a study by Sheffer et al., the rate of completion of 3month therapy was $40 \%$ and the successful use of the therapy was found to be associated with maintaining communication [23]. Proactive calls have been shown to increase the rate of success [24]. Low compliance to treatment is remarkable in the current study. This might have resulted from the great number of submissions in the campaign period and the lack of proactive calls. In the current study, the rate of success was significantly higher in those who used the medication for longer than 45 days. In a study by Stapleton et al., the 6-month uninterrupted success rate of participants who completed the therapy was determined as $37.9 \%$, while this rate was only $15.6 \%$ in those who discontinued the medication early. In this respect, it can be said that the current study is in parallel with literature [25].

When the subjects who used the medications for 45 days or longer were evaluated, the one-year success rate based on 7-day point prevalence was similar between the groups. In literature, the one-year success rate based on 7-day point prevalence has been reported as $26.2-30.5 \%$ for varenicline and $20.7-35 \%$ for bupropion. The results of the current study are consistent with literature in this respect $[18,20,21]$.

In the current study, $31.5 \%$ of the participants reported that they stopped using the medications because of side effects. No statistically significant difference was observed between the two medications in terms of side effects and quitting the medication because of side effects. In a systematic review by Lei et al. [11] discontinuation because of adverse events (RR, 1.34;95\% CI, 1.02-1.75) was significantly more common for the nonNRT group, which experienced more serious adverse 
events (RR, 1.87; 95\% CI, 1.08-3.24), compared with the control group. As NRT was not used in the current study, a comparison could not be made. Other reasons for not using the medications regularly were lack of confidence in oneself and belief that there was no further need of treatment $(21.8 \%)$ in the varenicline group and not seeing any benefit from the medication use (13.3\%) in the bupropion group. However, the rate of persons who joined the campaign because it was free of charge although they did not feel ready to quit smoking or did not believe that the medication would be effective was $10.1 \%$. In a previous study, the most important reason for discontinuation of the medication was starting smoking again $(41.6 \%)$ [26]. Other common causes included side effects of the medication and the belief that no further treatment was required. The rate of smoking has been reported to be high among alcohol and substance abusers which makes smoking cessation difficult [27]. In the current study, smoking cessation was achieved by 5 (7.9\%) alcohol abusers and $21.9 \%$ of individuals who did not drink alcohol and the difference was statistically significant.

It has been reported in literature that those who are confident in their ability to quit smoking are more successful [28]. Consistent with the literature, subjects in the current study with self-confidence about smoking cessation were found to be more successful. According to Prochaska [29] and Hymowitz [30], the more attempts that are made to quit smoking, the higher the rate of success will be. Similarly in the current study, the difference in the rate of success was statistically significant in respect of the number of attempts to quit smoking.

Although the results of this study are in parallel with reports in literature, there were some limitations to the study. The sudden increase in patient numbers due to the campaign and not being able to make sufficient proactive follow-up calls for continuous monitoring can be considered to have seriously reduced the success rates. Despite giving the patients appointment cards for the follow-up visits and emphasising the importance of those monitoring visits, the rate of those attending follow-up visits remained low. The significant factors for this situation were found to be the over-subscription of patients in the campaign period, a single doctor was attending a large number of patients and that proactive follow-up telephone calls could not be made. Previous studies have shown that proactive calls in the support of smoking cessation were related to an increase in success rates $[24,31,32]$.

\section{Conclusion}

At the end of the first year, no significant difference was found between the medications in terms of the success of smoking cessation. The rate of success of both the medications was consistent with literature. Persons who used the medications for longer than 45 days were more successful than those used them for shorter periods. In this study, the rate of compliance to treatment was lower compared to previous reports in literature. This may be attributable to the participation of the individuals without fully matured thoughts of quitting, purely because of the free-of charge distribution of the medications and also the low mean age of the participants. The lack of proactive calls might also have been a factor affecting compliance. The free of charge smoking cessation program launched by the Ministry of Health has created awareness. Although no significant difference was observed between the medications in terms of smoking cessation, the very low compliance to treatment suggests that such campaigns should be re-organized using different strategies.

\section{Abbreviatıons}

FTND: Fagerstrom test for nicotine dependence; NRT: Nicotine replacement therapy

\section{Acknowledgement}

Not applicable.

Funding

No funding.

Availability of data and materials

Please contact author for data requests.

Authors' contributions

All authors contributed equally during the preparation of this manuscript. Data were collected by Selman Erturhan. All authors read and approved the final manuscript.

\section{Competing interests}

The authors declare that they have no competing interests.

Consent for publication

Not applicable.

Ethics approval and consent to participate

Approval for this study was granted by the Local Ethics Committee, Cumhuriyet University Clinical Research at 10 January 2011 with reference number 2011-01/08.

Participants were informed and verbal consents were taken.

\section{Author details}

'Department of Family Medicine, Karabuk University, Medical Faculty, 78000 Karabuk, Turkey. ${ }^{2}$ Altinyayla State Hospital, Altinyayla, 58470 Sivas, Turkey.

${ }^{3}$ Etimesgut State Hospital, Etimesgut, 06790 Ankara, Turkey. ${ }^{4}$ Cekerek Primary Care Unit, Cekerek 66500, Yozgat, Turkey. ${ }^{5}$ Department of Family Medicine, Cumhuriyet University, Medical Faculty, 58000 Sivas, Turkey.

Received: 21 February 2016 Accepted: 21 January 2017

Published online: 01 February 2017

\section{References}

1. O'Brien CP, Gardner EL. Critical assessment of how to study addiction and its treatment: human and non-human animal models. Pharmacol Ther. 2005;108(1):18-58. doi:10.1016/j.pharmthera.2005.06.018.

2. Hecht SS. Tobacco smoke carcinogens and lung cancer. J Natl Cancer Inst. 1999:91(14):1194-210. doi:10.1093/jnci/91.14.1194.

3. Bektas M, Ozturk C, Armstrong M. An approach to children's smoking behaviors using social cognitive learning theory. Asian Pac J Cancer Prev. 2010;11(4):1143-9. 
4. Yengil E. Smoking among medical school students and attitudes against smoking. Konuralp Tıp Dergisi (in Turkish). 2014;2014(3):1-7. Available from: http://dergipark.ulakbim.gov.tr/ktd/article/viewFile/5000136361/5000125218.

5. Elbek O, Kılınç O, Aytemur ZA, Akyıldız L, Küçük ÇU, Özge C, et al. Tobacco control in Turkey. Turk Thorac J. 2015;16:141-50. doi:10.5152/ttd.2014.3898.

6. Uysal MA, Kadakal F, Karsidag C, Bayram NG, Uysal O, Yilmaz V. Fagerstrom test for nicotine dependence: reliability in a Turkish sample and factor analysis. Tuberk Toraks. 2004;52(2):115-21.

7. Perkins KA, Karelitz JL, Jao NC. Optimal carbon monoxide criteria to confirm 24-hr smoking abstinence. Nicotin Tob Res. 2013;15(5):978-82. doi:10.1093/ntr/nts205.

8. Fiore MC, Jaén CR, Baker TB, Bailey WC, Benowitz N, Curry SJ et al. Treating Tobacco Use and Dependence: 2008 Update, Clinical Practice Guideline. Hartford CT U.S. Department of Health and Human Services, Public Health Service; 2009. https://books.google.com.tr/books?hl=tr\&lr=\&id=dUl4JJzlsikC \&oi=fnd\&pg=PR1\&dq=Treating+Tobacco+Use+and+Dependence:+2008 +Update\&ots=TqDBe95tL_\&sig=j18DnqMc9hnKLxihNPZi1nvShcw\&redir_ esc=y\#v=onepage\&q=Treating\%20Tobacco\%20Use\%20and\%20Dependence \%3A\%202008\%20Update\&f=false.

9. Keely JP, Hughes JR, Carpenter MJ. A method to convert prolonged abstinence and point prevalence quit rates. Nicotin Tob Res. 2001;3:272-3.

10. Cahill K, Stevens S, Perera R, Lancaster T. Pharmacological interventions for smoking cessation: an overview and network meta-analysis. Cochrane Database Syst Rev. 2013;5:CD009329. doi: 10.1002/14651858.CD009329.pub. http://onlinelibrary.wiley.com/doi/10.1002/14651858.CD009329.pub2/pdf.

11. Wu L, Sun $S$, He Y, Zeng J. Effect of smoking reduction therapy on smoking cessation for smokers without an intention to quit: an updated systematic review and meta-analysis of randomized controlled trials Int. J Environ Res Public Health. 2015;12:10235-53. doi:10.3390/ijerph120910235.

12. Hughes JR, Stead LF, Hartmann BJ, et al. Antidepressants for smoking cessation. Cochrane Database Syst Rev. 2014;8(1):CD000031. doi: 10.1002/ 14651858.CD000031.pub4.

13. Ottawa (ON). Nicotine Replacement Therapy, Bupropion and Varenicline for Tobacco Cessation: A Review of Clinical Effectiveness. Canadian Agency for Drugs and Technologies in Health. 2016 Mar 08.PMID: 27077161

14. Sağlam L. Investigation of the results of a smoking cessation clinic and the factors associated with success. Turk J Med Sci. 2012;42:515-22. doi:10.3906/sag-1101-1452.

15. Hagimoto A, Nakamura M, Morita T, Masui S, Oshima A. Smoking cessation patterns and predictors of quitting smoking among the Japanese general population: a 1-year follow-up study. Addiction. 2010;105(1):164-73. doi:10.1111/j.1360-0443.2009.02735.x.

16. Salepçi B, Fidan A, Oruc O, Torun E, Çağlayan B, Kader ŞN. Success rates in our smoking cessation clinic and factors affecting it. Turkish Thoracic J. 2005:6:151-8.

17. Kökten R. Trakya Üniversitesi Tıp Fakültesi Sigara Bırakma Polikliniği çalışmalarının değerlendirilmesi. 2008. Available from: http://193.255.140.91: 8080/jspui/handle/1/479

18. Jorenby DE, Hays JT, Rigotti NA, Azoulay S, Watsky EJ, Williams KE, et al. Efficacy of varenicline, an alpha4beta2 nicotinic acetylcholine receptor partial agonist, vs placebo or sustained-release bupropion for smoking cessation: a randomized controlled trial. JAMA. 2006;296(1):56-63. doi:10.1001/jama.296.1.56.

19. Fidan F, Ebru P, Mehmet Ü, Sezer M, Ziya K. Factors Affecting Smoking Cessation and Success Rates of The Treatment Methods Used. Kocatepe Tıp Dergisi (in Turkish). 2005;6(3):27-34. Available from: http://www.kocatepetipdergisi. aku.edu.tr/PDF/Eylul\%202005/27-34\%20Fatma\%20Fidan.pdf.

20. Rigotti NA, Pipe AL, Benowitz NL, Arteaga C, Garza D, Tonstad S. Efficacy and safety of varenicline for smoking cessation in patients with cardiovascular disease a randomized trial. Circulation. 2010;121(2):221-9. doi:10.1161/CIRCULATIONAHA.109.869008.

21. Gonzales D, Rennard SI, Nides M, Oncken C, Azoulay S, Billing CB, et al. Varenicline, an a4 $\beta 2$ nicotinic acetylcholine receptor partial agonist, vs sustained-release bupropion and placebo for smoking cessation: a randomized controlled trial. JAMA. 2006;296(1):47-55. doi:10.1001/jama.296.1.47.

22. Lee J-Y, Kim MJ, Jun H-J, Kang M, Park AR, Oh DE, et al. Adherence to varenicline and abstinence rates for quitting smoking in a private health promotion center-based smoking cessation clinic. Tuberc Respir Dis (Seoul). 2012:72(5):426-32. doi:10.4046/trd.2012.72.5.426.
23. Sheffer CE, Stitzer M, Landes R, Brackman SL, Munn T, Moore P. Socioeconomic disparities in community-based treatment of tobacco dependence. Am J Public Health. 2012;102(3):8-16. doi:10.2105/AJPH.2011.300519.

24. Pan W. Proactive telephone counseling as an adjunct to minimal intervention for smoking cessation: a meta-analysis. Health Educ Res. 2006; 21(3):416-27. doi:10.1093/her/cyl040.

25. Stapleton J, West R, Hajek P, Wheeler J, Vangeli E, Abdi Z, et al. Randomized trial of nicotine replacement therapy (NRT), bupropion and NRT plus bupropion for smoking cessation: effectiveness in clinical practice. Addiction. 2013;108(12):2193-201. doi:10.1111/add.12304.

26. Rose JE, Behm FM, Westman EC. Nicotine-mecamylamine treatment for smoking cessation: the role of pre-cessation therapy. Exp Clin Psychopharmacol. 1998;6(3):331-43. doi:10.1037/1064-1297.6.3.331.

27. Dollar KM, Homish GG, Kozlowski LT, Leonard KE. Spousal and alcohol-related predictors of smoking cessation: a longitudinal study in a community sample of married couples. Am J Public Health. 2009;99(2):231-3. doi:10.2105/AJPH.2008.140459.

28. Li L, Borland R, Yong H-H, Fong GT, Bansal-Travers M, Quah AC, et al. Predictors of smoking cessation among adult smokers in Malaysia and Thailand: findings from the International Tobacco Control Southeast Asia Survey. Nicotin Tob Res. 2010;12(1):34-44. doi:10.1093/ntr/ntq030.

29. Prochaska JO, DiClemente CC, Velicer WF, Ginpil S, Norcross JC. Predicting change in smoking status for self-changers. Addict Behav. 1985;10(4):395-406. doi:10.1016/0306-4603(85)90036-X.

30. Hymowitz N, Cummings KM, Hyland A, Lynn WR, Pechacek TF, Hartwell TD. Predictors of smoking cessation in a cohort of adult smokers followed for five years. Tob Control. 1997;6(2):57-62. doi:10.1136/tc.6.suppl_2.S57.

31. Peterson Jr AV, Kealey KA, Mann SL, Marek PM, Ludman EJ, Liu J, Bricker JB. Group-randomized trial of a proactive, personalized telephone counseling 112 intervention for adolescent smoking cessation. J Natl Cancer Inst. 2009; 101(20):1378-92.

32 Stead LF, Perera1 R, Lancaster T. Telephone counselling for smoking cessation. Cochrane Database Syst Rev. 2006:CD002850. DOI: 10.1002/ 14651858.CD002850.pub2 Available from: http://onlinelibrary.wiley.com/doi/ 10.1002/14651858.CD002850.pub2/full.

\section{Submit your next manuscript to BioMed Central and we will help you at every step:}

- We accept pre-submission inquiries

- Our selector tool helps you to find the most relevant journal

- We provide round the clock customer support

- Convenient online submission

- Thorough peer review

- Inclusion in PubMed and all major indexing services

- Maximum visibility for your research

Submit your manuscript at www.biomedcentral.com/submit
) Biomed Central 